\title{
Inserted defects in bone after radiotherapy using exoelectron emission technique
}

\author{
M. ZAKARIA ${ }^{1}$, Y. DEKHTYAR $^{1}$, V. NOSKOV ${ }^{1}$, T. BOGUCHARSKA $^{1}$
}

(Manuscript received 6 May 2008, accepted 4 July 2008)

\begin{abstract}
This article deals with the estimation of inserted defects in bone material by photons used for radiation therapy, for instance, to treat carcinogenic diseases including bone cancer. However, there are side effects by radiation on structures of bones. Structure alters electron density of states that, in time, influences biomedical reactions on bone life condition. Exoelectron emission (EEE) phenomenon underlies a new electron spectroscopy to explore alteration of the electronic structurally dependence properties of bone material. The influence of photons with different energies and the dose rate on the bone structure is discussed. The bone EEE response is not linear on the dose rate and probably is connected with interaction of radiation induced centers responsible for EEE process. EEE structural changes have varied with energy variety of doses used in radiotherapy.
\end{abstract}

Keywords: X-ray / radiotherapy / exoelectron emission / dose rate / photons / bone

RÉSUMÉ Estimation des défauts introduits dans l'os après une radiothérapie, au moyen d'une technique d'émission exoélectronique.

Cet article porte sur l'estimation des défauts introduits dans le matériau de l'os par les photons employés en radiothérapie, par exemple, pour soigner des maladies carcinogènes, voire un cancer osseux ; il y a des effets secondaires du rayonnement sur la structure de l'os. La structure altère la densité électronique d'états ; cette altération influence, à son tour, les réactions biomédicales qui agisse sur la condition de vie de l'os. Le phénomène d'émission d'exo-électrons (EEE) sous-tend une nouvelle spectrométrie électronique permettant d'explorer l'altération des propriétés de dépendance électronique structurelle du matériau de l'os. Nous étudions l'influence de l'énergie et du débit de dose des photons sur la structure de l'os. La réponse EEE de l'os n'est pas une fonction linéaire du débit de dose ; elle est probablement associée à l'interaction de centres responsables du processus EEE, induits par le rayonnement. Les modifications structurelles EEE ont varié avec les énergies et les doses employées en radiothérapie.

\section{Introduction}

High energy X-rays used in radiotherapy (energy ranging up to about $20 \mathrm{MeV}$ ) does not kill the cancer cells only, but they also have effects on the structures of bones. Structure alters electron density of states that, in time, influences biomedical reactions on bone life condition. Due to this reason, biochemical reactions between the bone and the surrounding cells targeted to remodel tissue

\footnotetext{
1 Institute of Biomedical Engineering and Nanotechnologies, Riga Technical University, Kalku Street 1, Riga 1658, Latvia.
} 
could be influenced (Eriksen and Kassem, 1992). A bone surface, where the cells are coming to be adhered (Schakenraad, 1996) with the aim to supply biochemical reactions (Demster, 2000), has the greatest impact.

Radiation stimulated processes are initiated due to generation of single imperfections such as vacancies, interstitial atoms, radicals, etc. in a very short time (Dekhtyar and Katashev, 1996). According to Dekhtyar and Katashev (1997), inserted defects facilitate diffusion-controlled reaction developed in the long-time scale to move a solid material into the state of thermodynamically equilibrium. The exoemission analysis is widely used for irradiated semiconductors as siliceous, carbon plastic-reinforced material and natural bone composites. In all these cases, the total exoemission-related charge is directly proportional to the number of radiation-inserted imperfections and has wave-type regularity on dependence of the exposure (Dekhtyar, 2000).

The aim of this article is to show the development of EEE measurement technique and the way it is used for investigating X-ray irradiated bones. Moreover, it aims to show the X-ray irradiation modes that may insert defects on bone structure.

\section{Material and methods}

\subsection{Technology to prepare bone specimens}

To investigate the gamma radiation effects, the bovine bone had been chosen as a prototype for the human ones. The bovine bone has components and structure similar with human bone according to Katz (1995). The bovine tibia bone of slithered 1.5 years old cow was used as a material for the experiments. The bovine bone was bought after two days the animal was slithered. Then, it was cleaned mechanically from muscles, fat and bone marrow. Specimens were cut transversally to the bone longitudinal axis using either stainless steel surgical saw or facing tool. They have the same physical parameters: thickness $(A)$ of $0.2 \mathrm{~cm}$, surface area $(B)$ of $0.36 \mathrm{~cm}^{2}$, volume of $0.72 \mathrm{~cm}^{3}$ and mass density of about 1.5 $1.7 \mathrm{~g} / \mathrm{cm}^{3}$ since it is without bone marrow (Fig. 1).

\subsection{Exoelectron spectrometer}

Measurements were performed using the exoemission technique which was described in details by Dekhtyar (1981). Exoelectron spectrometer consists of a vacuum system, a complex of electronic devices for the EEE intensity registration, as well as the record of the received information blocks of a photo- and thermostimulation (Figs. 2 and 3). 
INSERTED DEFECTS IN BONE

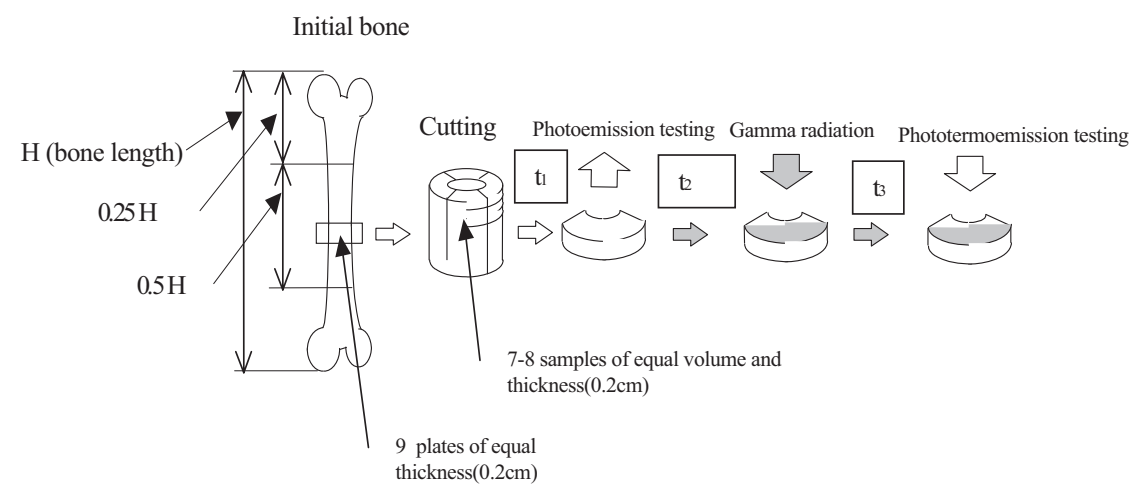

Figure1 - Technology of preparation and emission testing of the model specimens.

Technologie de la préparation et du contrôle de l'émission des spécimens pris pour modèles.

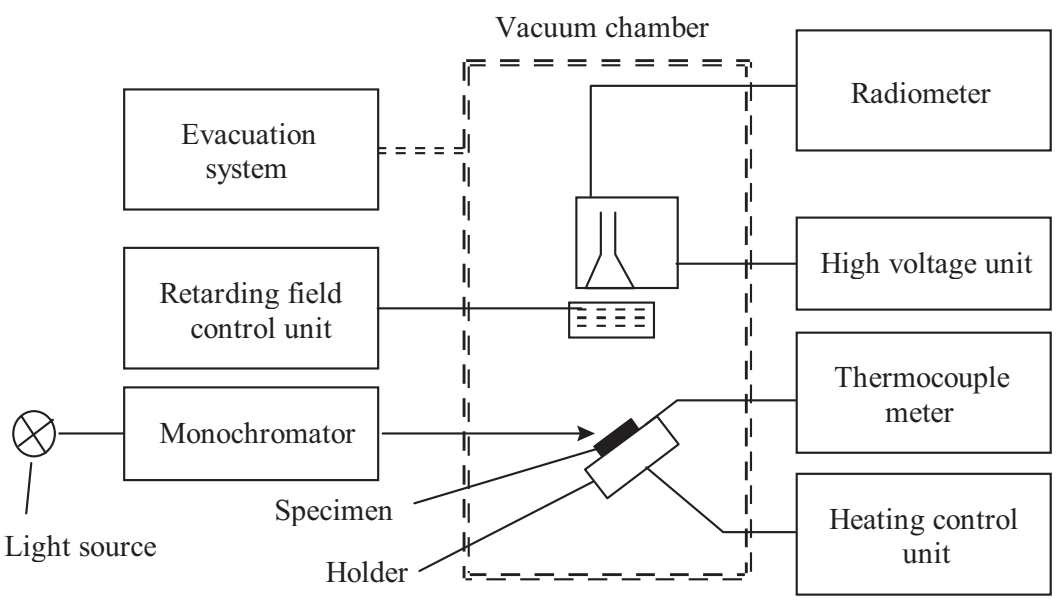

Figure 2 - The scheme of the exoelectron spectrometer.

Schéma du spectromètre exo-électronique.

As shown in Figures 2 and 3, the exoelectron spectrometer consists of the following parts.

\subsubsection{Vacuum system}

Minimal pressure $v$, vacuum chamber, $\sim 10^{-4} \mathrm{~Pa}$ and was checked by ionization transducer PMT-2 connected with vacuumeter VIT-2. Vacuum provided by means 


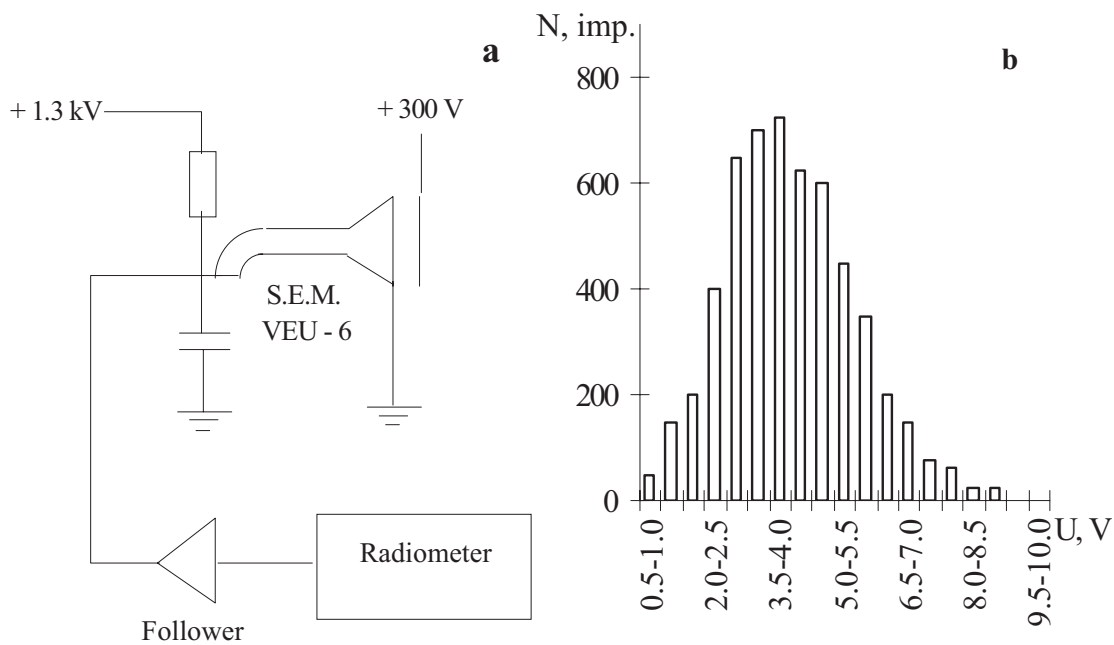

Figure 3 - Usage of secondary electron multiplier (SEM): (a) the scheme of electronic connection; (b) the distribution of SEM impulses on its amplitudes $U$.

Emploi du multiplicateur à électrons secondaires (SEM); (a) schéma de la connexion électronique ; (b) distribution, en fonction de leur amplitude $U$, des impulsion SEM.

of mechanical rotator pump and diffusion pump. Vacumation time was not more 15 minutes.

\subsubsection{Table for sample}

Sample is placed on by cubic form table from copper, fixed on the hollow steel tube. It has an open to provide access for the outside thermostimulation. Specimens was pinned to the surface by a special holder, made from the annealed stainless. The incidence of light beam was fixed due to the table design at $45^{\circ}$.

\subsubsection{Photostimulation system}

The source of light is deuterium UF lamp DDS-30 with a power equal to $30 \mathrm{~W}$. This arrangement provides photon energies within continuous spectra of $3.1 \div 6.2 \mathrm{eV}$ with the accuracy equal to $\pm 2 \%$. Light through quarts focusing system penetrates through diffraction monochromator and focused by quarts lens, mounted in vacuum chamber on the sample surface. UV zone diameter $\left(d_{z \min }=\right.$ $0.1 \mathrm{~cm})$ are regular. 


\subsubsection{Thermostimulation system}

Thermostimulation of sample is applied to a specimen placed in vacuum chamber by halogen lamp (of power about $600 \mathrm{~W}$ ) with the help of heater power supply, linear heating controller and thermocouple. Heater power provides linear heating of sample by rate $0.1-0.5{ }^{\circ} \mathrm{C} / \mathrm{s}$ in temperature ranging from 293 to $673{ }^{\circ} \mathrm{C}$. Temperature measurements, in ${ }^{\circ} \mathrm{C}$, were provided with thermocouple.

$$
\begin{gathered}
{[U]=\mathrm{mV},} \\
T=24.5 \Delta U .
\end{gathered}
$$

From the above formula, one could get the uncertainty of $T$ which is $(\Delta T)$. Because $\Delta U=10^{-2} \mathrm{mV}$, then $\Delta T \approx 0.3^{\circ} \mathrm{C}$.

\subsubsection{Electron emission registration system (EERS)}

As a detector of electrons, amplifier VEU-6 is used. It is used to count the impulses detected. Its main characteristics are the followings:

- dark light of $0.1 \mathrm{imp} / \mathrm{s}$;

- coefficient of amplifier is $7 \times 10^{8}$;

- maximal voltage supply $\left(V_{s}\right)$ equal to $4000 \mathrm{~V}$;

- maximal impulse intensity $\left(I_{\text {imp }}\right)$ is $10^{5}$;

- magnitudes allowed $I_{i m p}$ untill $10^{4} \mathrm{imp} / \mathrm{s}$ and $V_{s}=2400 \mathrm{~V}$.

The power supply for VEU is stabilising block supply "high voltage power supply", which allows providing regular supply voltage from 0 to $4000 \mathrm{~V}$. Signal from input VEU through a specific preamplifier penetrates to radiometer which provides impulse counting during the known interval of time that makes the results appear in the form of digital table.

For collection of electrons by VEU, low voltage power supply (voltage $+200 \mathrm{~V}$ ) is used.

PTSE spectra are registered by "recorder". Due to Poissons statistics of the single-particles impulses, the uncertainty of emission current measurement is equal to the square root from the measured number of particles.

In the present work, measurements of EEE were performed in vacuum conditions because of low emitted electron energy. Thus, the vacuum electron spectrometer was required. Specimens were pinned to the surface of a special holder, made from the annealed copper, fixed on the hollow steel tube. It has an open to provide access for the outside thermostimulation. The later was supplied 
by the tungsten filament lamp (power $450 \mathrm{~W}$ ), inserted in the above tube. Thus, the lamp was isolated from the vacuum chamber, and, correspondingly, from the particle counter. The programmable temperature controller used to provide a linear heating mode governing the lamp. The temperature of the table was measured by the chromel-alumel thermocouple, referred on the melting ice temperature. A thermo-induced difference of potentials was recorded by the potentiometer and it was recorded in degrees Celsius.

The current of the emitted particles was measured by the channel secondary electron multiplier VEU-6, operated in the single electron counting mode. The high potential $(+150 \mathrm{~V})$ on the multiplier input serves to collect electrons. The output signal was amplified and further recorded by the radiometer in the form of numerical readout and on the plotter. A supply voltage of the multiplier $(+3.2 \mathrm{kV})$ and discrimination level of the radiometer $(0.5 \mathrm{~V})$ were selected to provide well (centred one) peak distribution of multiplier output impulses amplitudes. Such a distribution proves, that the multiplier operates in one-electron mode and a signal may be lost due to restriction of noise impulses (amplitude smaller then $0.5 \mathrm{~V}$ ) is negligible. The uncertainty of emission current measurement is equal to the square root from the measured number of particles, due to the Poisson statistics of the single-particles impulses.

Analysis of the escaped particles energy was performed by means of the flat, four-grid linear analyser with the retarding potential. It was mounted in the front of the particle detector to provide the grids placed in parallel to the specimen surface, the photostimulating light spot being on the analyser axis. The input aperture of the analyser had a diameter of $8 \mathrm{~mm}$. Such a large aperture obviously causes some inaccuracy of the energy measurement because non-paraxial particles detection. Besides, due to a weak intensity of the photocurrent from the bone there was no possibility to use a smaller aperture. An imperfection of analyser was minimised by the appropriate configuration of electric potentials, applied to the grids. Ideal curves and retarded curves (dependencies of the emission current $I$ on the potential $U$ ) of the analyser are presented in Figure 3. Configuration of the potentials was selected to minimise the slope of the plateau and simultaneously maximise the output current.

\subsection{Optimization of exoemission measurements}

The bone material has specific EEE measurement technology. Exoemission measurements should be carried out after the 10th day of storage of the samples at room conditions after irradiation (Zakaria et al, 2006a; Zakaria, 2007). The heating cycle has an effect on the exoemission response and the measurements cannot be performed after the 1st heating cycle (Zakaria, 2007). Heating of the specimens up 
to $+200{ }^{\circ} \mathrm{C}$ during EEE measurement change the bone emission properties in the irreversible manner (Zakaria, 2007). To perform the calibration of the specimens before and after irradiation, the EEE current ( $I$ ) was measured using only photostimulation and blank measurements of specimens were also done without irradiation (Zakaria et al., 2005, 2006b).

To evaluate the final value of imperfections inserted by X-ray radiation in bone material, the photo- and thermo-stimulation were applied simultaneously. Square of the area under the EEE graph is directly proportional to the total number of electrons $(Q)$ emitted during EEE measurement:

$$
Q=\int_{T_{0}}^{T_{f}} I(T) d T
$$

where $T_{0}$ and $T_{f}$ are the initial and the final temperatures of EEE spectrum, respectively. The total number of electrons $(Q)$ emitted during EEE measurement is directly proportional to the concentration of the inserted by gamma radiation defects (Dekhtyar, 1981). Standard uncertainty of exoemission measurement was $4 \%$ with the level of significance of $95 \%$.

Moreover, some factors that might influence our final results were considered. These factors are: duration of bone storage, temperature dependence, heating rate conditions, and photon energy (Bogucharska et al., 2000).

After several experiments had been applied at the laboratory of Biomedical Engineering and Nanotechnology Institute of Riga Technical University, an optimization was performed to get the highest exoemission maxima and reproducible results. These conditions are listed below (Zakaria, 2007):

- exoemission measurements should be conducted after the 10th day of bone storage,

- the energy of photons should be equal to $5.6 \mathrm{eV}$,

- measurements should be done at the 1 st heating cycle,

- rate of heating should be equal to $10^{\circ} \mathrm{C} / \mathrm{min}$.

\subsection{Description of the irradiation procedure}

Irradiations (Tab. I) were performed at Latvia National Oncology Centre using a linear accelerator Philips SL75-10 (8 MV) and Varian Clinac 2100CD (6 and $18 \mathrm{MV})$. The beam is pulsed with duration of 2 microseconds and repetition rates selectable between 100 and 600 per second. In the photon mode, the dose rate was 
TABLE I

Plan for X-ray irradiation of bone specimens.

Programme de l'irradiation par rayons $\mathrm{X}$ de spécimens d'os.

\begin{tabular}{|c|c|c|c|c|}
\hline Irradiation mode & $\begin{array}{c}\text { Number } \\
\text { of specimens }\end{array}$ & $E, M V$ & $D, \mathbf{G y}$ & $\dot{D}, \mathrm{~Gy} / \mathrm{min}$ \\
\hline \multicolumn{5}{|l|}{ Fractional } \\
\hline Experiment \#1 & 27 & $\begin{array}{r}8 \text { (typical for } \\
\text { radiotherapy) }\end{array}$ & $2,4,6,8,10$ & $\begin{array}{c}1,2 \text { (typical for } \\
\text { radiotherapy) }\end{array}$ \\
\hline \multicolumn{5}{|l|}{ Non-fractional } \\
\hline Experiment \#2 & 69 & 6 & $2,4,6,8,10$ & $2,3,4,6$ \\
\hline Experiment \#3 & 27 & 8 & $2,4,6,8,10$ & 2 \\
\hline Experiment \#4 & 27 & 8 & $\begin{array}{l}1,2,3,4,5, \\
6,7,8,9,10\end{array}$ & 2 \\
\hline Experiment \#5 & 69 & 18 & $2,4,6,8,10$ & $1,2,4,6$ \\
\hline
\end{tabular}

approximately 10 Gy per minute measured at 1 metre from the target at a depth in a water phantom at a depth of $10 \mathrm{~cm}$. In the electron mode, dose was equivalent to $\sim 0.3$ Gy (30 rads) per pulse.

\section{Results and discussion}

\subsection{Behaviour of the parameter " $Q$ " for both fractional and non-fractional modes}

Figure 4 shows the $Q$ behavior for fractional and non-fractional modes for $E$ equal to $8 \mathrm{MV}$. The deviation of $Q$ for different dose rates at fractional mode was close to the uncertainty of $\Delta Q$. Moreover, the deviation of $Q$ for the dose rate $2 \mathrm{~Gy} / \mathrm{min}$ both for fractional and non-fractional modes was close to $\Delta Q$. Due to that, we concluded not to continue experiments with $8 \mathrm{MV}$ modes. Additional to that, since the fractional mode is typically applied for live system and these bone specimens are not alive ones, and because there are no significant differences between the graphs in Figure 4, it was decided not to carry on further experiments using fractional mode but only non-fractional mode.

\subsection{Infuence of $X$-ray radiation on parameter " $Q$ "}

Figure 5 shows the structural changes inserted in the bone material by X-ray photons radiation with energy equal to $6 \mathrm{MV}$ described by total emitted charge $Q$. The experiments were performed with different absorbed dose rates $2 \mathrm{~Gy} / \mathrm{min}$ and $6 \mathrm{~Gy} / \mathrm{min}$. According to the results, one can conclude that EEE has a linear response when the dose rate is $6 \mathrm{~Gy} / \mathrm{min}$ but does not have the response at 
INSERTED DEFECTS IN BONE

\section{$\mathrm{E}=8 \mathrm{MeV}$}

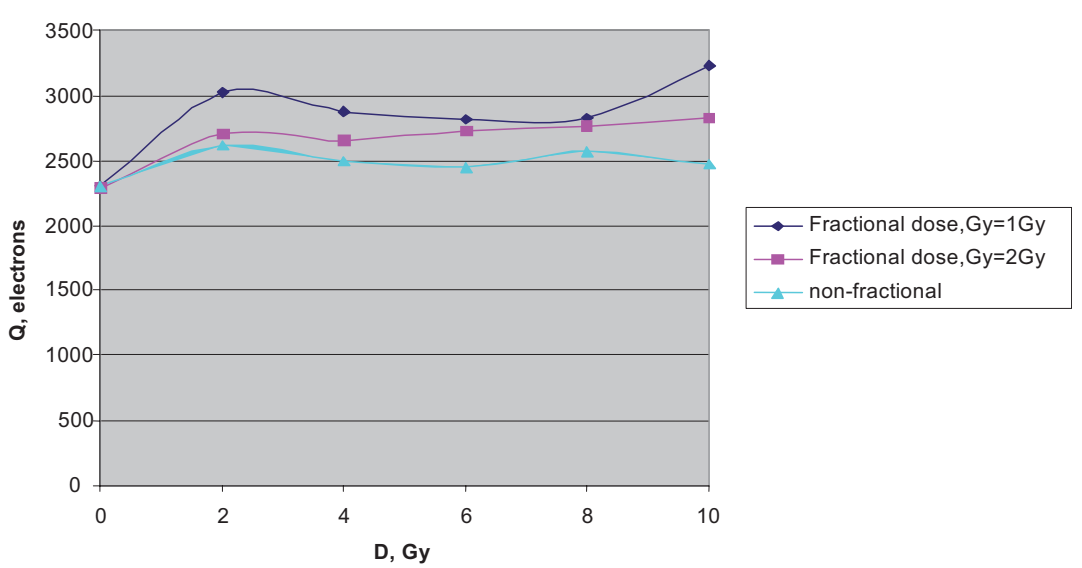

Figure 4-Dependence of the $Q$ average values (3-5 measurements for each dot) on D for $E=8 M V$ for fractional and non-fractional modes.

Variation des valeurs moyennes $Q$ (3 à 5 mesures pour chaque point) en fonction de $D$, pour $E=8 \mathrm{MV}$ et des modes fractionnaires ou non.

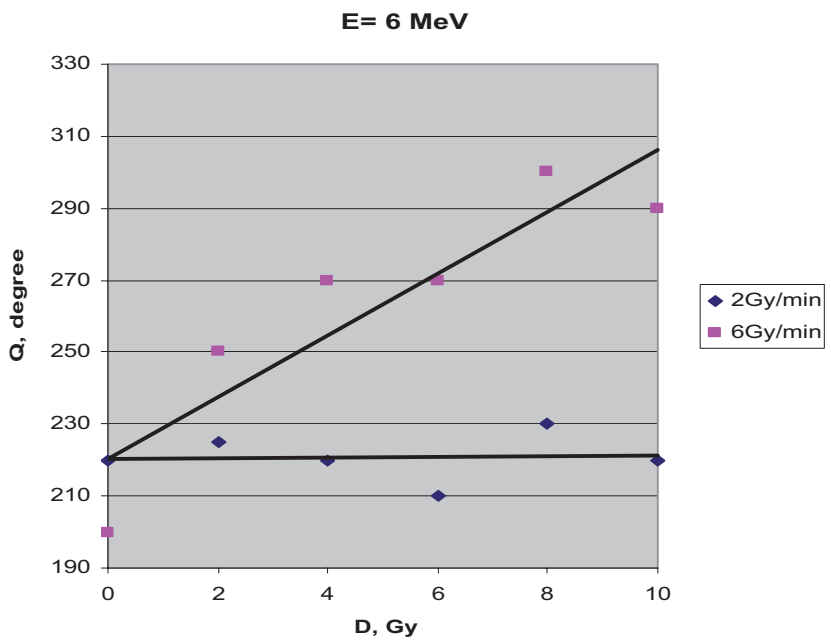

Figure 5 - Dependence of the $Q$ average values (3-5 measurements for each dot) on $X$-ray radiation absorbed dose (D) of gamma photon for $E=6 \mathrm{MV}$ and absorbed dose rates $\left(\dot{D}_{\min }=2 \mathrm{~Gy} / \mathrm{min}\right.$ and $\dot{D}_{\text {max }}=6$ Gy/min).

Variation des valeurs moyennes $Q$ (3 à 5 mesures pour chaque point) en fonction de la dose absorbée $D$ pour des photons $X$ de $E=6 \mathrm{MV}$ et des débits de dose absorbée de $2 \mathrm{~Gy} / \mathrm{min}$ et $6 \mathrm{~Gy} / \mathrm{min}$. 


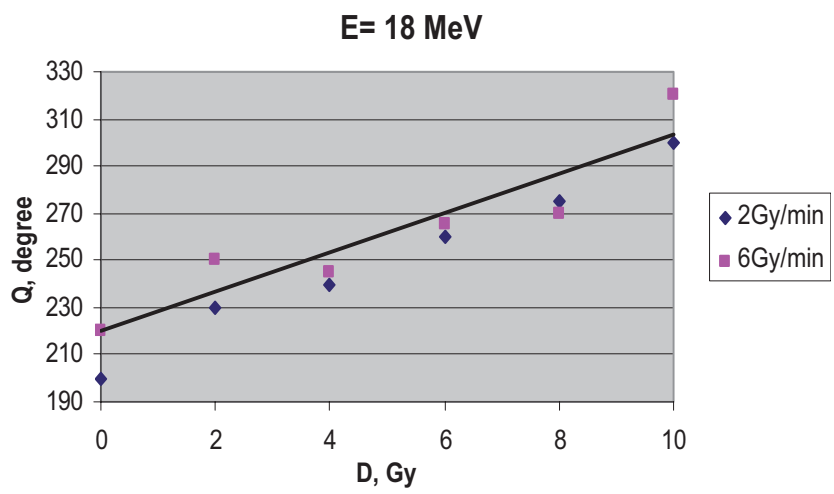

Figure 6-Dependence of the $Q$ average values (3-5 measurements for each dot) on $X$-ray radiation absorbed dose $(D)$ of gamma photon for $E=18 \mathrm{MV}$ and absorbed dose rates $\left(\dot{D}_{\min }=2 \mathrm{~Gy} / \mathrm{min}\right.$ and $\dot{D}_{\text {max }}=6$ Gy/min).

Variation des valeurs moyennes $Q$ (3 à 5 mesures pour chaque point) en fonction de la dose absorbée $D$ pour des photons $X$ de $E=18 \mathrm{MV}$ et des débits de dose absorbée de $2 \mathrm{~Gy} / \mathrm{min}$ et $6 \mathrm{~Gy} / \mathrm{min}$.

$2 \mathrm{~Gy} / \mathrm{min}$. In case of magnitude, X-ray photon energy equals to $6 \mathrm{MV}$ with different absorbed dose rates does not affect the number of radiation inserted imperfections.

Figure 6 shows the $Q$ behaviour of bone material after irradiation by gamma photons with energy $E=18 \mathrm{MV}$. Radiation had been performed with different dose rate $(2 \mathrm{~Gy} / \mathrm{min}$ and $6 \mathrm{~Gy} / \mathrm{min}$ respectively). The data on Figure 6 gives the evidence that EEE linear responses for the dose rates both $2 \mathrm{~Gy} / \mathrm{min}$ and $6 \mathrm{~Gy} / \mathrm{min}$ are similar and demonstrate linear correlation. It is clearly seen that the same gamma radiation dose rates has influence on generation of imperfection in bone material.

\section{Conclusion}

The exoelectron spectrometer could detect the inserted defects on bone material of $\mathrm{X}$-ray radiation exoelectron emission signal of the bone material is affected by gamma radiation applied for radiation therapy. Exoelectron emission analysis could be applied to estimate radiation induced alteration of the bone structural properties with the aim of radiation therapy planning improvement and quality assurance provision. Exoelectron emission best application for radiation therapy lies in the ranges of gamma photons with energy of $6 \mathrm{MV}$ and dose rate $6 \mathrm{~Gy} / \mathrm{min}$ as well as of X-ray photon energy of $18 \mathrm{MV}$ and dose rate $\geq 2 \mathrm{~Gy} / \mathrm{min}$. It may be 
INSERTED DEFECTS IN BONE

assumed that the bone EEE response is not linear on the dose rate and probably is connected with interaction of radiation induced centers responsible for EEE process.

EEE structural changes varied with energy and dose rate varieties of doses used in radiotherapy. One may conclude that EEE has a linear response on $6 \mathrm{MV}$ radiation when the dose rate is $6 \mathrm{~Gy} / \mathrm{min}$ but does not have the response at $2 \mathrm{~Gy} / \mathrm{min}$. However at $18 \mathrm{MV}$, EEE lineary responses for the dose rates both $2 \mathrm{~Gy} / \mathrm{min}$ and $6 \mathrm{~Gy} / \mathrm{min}$ are similar.

\section{REFERENCES}

Bogucharska T., Dekhtyar Yu., Pavlenko A., Pavlenko I., Katashev A., Katasheva Yu., Zakaria M. (2000) Technology to prepare the bone for exoemission test, Latv. J. Phys. Tech. Sc. 6, 244-247.

Dekhtyar Yu. (1981) Exoelectron Emission of Silicon having Structural Defects, Ph.D. thesis, Riga Technical University, pp. 1-120.

Dekhtyar Yu. (2000) Exoemission for Studying Synergetic Phenomena, Riga, Latv. J. Phys. Tech. Sci. 6, 119.

Dekhtyar Y., Katashev A. (1996) Electron Structure of Bone Surface Layer Affected with Ultraviolet Radiation, Med. Biol. Engineer. Comp. 34, 177-178.

Dekhtyar Y., Katashev A. (1997) Exoemission Centers Discovered at Neutral Composite Material (Bone Tissue) Interface, Sci. Rep. Opole Tech. Univ. Ser. Phys. 20, 129-134.

Demster D.W. (2000) Remodeling of Bone, "Osteoporosis: Etiology, diagnosis and treatment", In B.L. Riggs, L.J. Melton III (Eds.). Nevskii Dialekt, St. Petersburg, Russian edition, pp. 85-108.

Eriksen E.F., Kassem M. (1992) The Cellular Basis of Bone Remodelling, Triangle 31, 45-57.

Katz J.L. (1995) The Biomedical Engineering Handbook, CRC Press Inc., J.D. Bronzino, pp. 273-289.

Schakenraad J.M. (1996) Cells: Their Surfaces and Interaction with Materials, "Biomaterials Science", In B.D. Ratner, A.S. Hoffman, F.J. Schoen, J.E. Lemons (Eds). Academic Press, San Diego, pp. 141-147.

Zakaria M., Bogucharska T., Noskov V., Dekhtyar Y. (2005) Technologies to Explore Gamma Radiation Influence on Structurally Depended Exoemission Properties of Bone, In J. Valentin (Ed.), proceedings of Nordic Society for Radiation Protection. Proceedings of the XIV ordinary meeting: Radiological Protection in Transition, Rättvik (Sweden), August 27-31, 2005. SSI Rapport 2005:5 Stockholm: Swedish Radiation Protection Authority, pp. 47-50.

Zakaria M., Dekhtyar Yu., Noskov V., Bogucharska T. (2006a) Exoemission Instrument and Technology To Explore Gamma Radiation Influence on Bones, Physica Medica XXII, 47-49.

Zakaria M., Dekhtyar Y., Bogucharska T., Noskov V. (2006b) Exploring Gamma Radiation Effect On Exoelectron Emission Properties Of Bone, Proceedings of the Second European International Radiation Protection Association IRPA Congress "Radiation protection: From Knowledge to Action", May 15-19, 2006, Paris, France.

Zakaria M. (2007) Exoemission Instrument and Technology to Explore Gamma Radiation Influence on Bones, Ph.D. thesis, RTU Printing House, ISBN 978-9984-32-721-1, Riga Technical University, Riga, Latvia. 